\title{
APLIKASI 3D ARTERIAL SPIN LABELING SEQUENCE PADA PEMERIKSAAN BRAIN MRI
}

\author{
Ary Nova Setiyanto ${ }^{1}$ Anita Nur Mayani ${ }^{2}$ \\ ${ }^{1}$ Rumah Sakit Adi Husada Undaan Wetan Surabaya \\ ${ }^{2}$ D3 Radiologi, STIKES Guna Bangsa Yogyakarta \\ Corresponding author: Ary Nova Setiyanto \\ Email: anitanurmayani@gmail.com
}

Received: written by editor; Revised: written by editor; Accepted: written by editor (date of submission, 10pt)

\begin{abstract}
Background: MRI (Magnetic Resonance Imaging) is a noninvasive diagnostic examination that utilizes high magnetic field strength in producing an image. Non-contrast Brain MRI Examination in Radiology Installation of Adi Husada Undaan Wetan Hospital Surabaya using a sequence of Ax DWI b1000 routines, Ax T2 Flair FS, Ax T2 Propeller, Ax T1 FSE, MRA TOF, Ax T2 * GRE. Clinical suspect CVA infarct, Brain MRI examination in Radiology Installation of Adi Husada Hospital Undaan Wetan Surabaya added 3D ASL sequences without using gadolinium contrast media.

Methods: This type of research is qualitative research with a case study approach. Data was taken from January to February 2019. The object of the study was MRI Brain examination in CVA infract cases at Radiology Installation at Adi Husada Undaan Wetan Hospital, Surabaya. The research subjects are 2 radiographers and 1 radiologist.

Results: Based on the results of visual analysis with interview methods with radiologists, the image results on Ax DWI b1000, Ax T2 Flair FS and Ax T2 Propeller appear hyperintense images which indicate the presence of pathology in the restricted area. The addition of the 3D ASL sequence is used to determine CBF (cerebral blood flow).

Conclusions : The application of the 3D ASL sequence to the clinical suspect CVA infarct with the right method can greatly assist the radiologist to diagnose patient abnormalities.
\end{abstract}

Keyword : 3D ASL; CVA infarct; CBF; Magnetic Resonance Imaging

\section{Pendahuluan}

MRI (Magnetic Resonance Imaging) merupakan pemeriksaan diagnostik non invasif yang memanfaatkan kekuatan medan magnet yang tinggi dalam menghasilkan suatu citra. Prinsip pencitraan MRI yaitu dengan memanfaatkan sifat kemagnetan organ tubuh manusia yang didominasi oleh atom hidrogen yang akan beresonansi saat diaplikasikan radiofrekuensi di dalam medan magnet. Hasil resonansi tersebut kemudian ditangkap kemudian diproses sehingga dihasilkan citra dengan kontras yang sangat baik bila dibandingkan dengan pencitraan dengan modalitas lain. Pada pemeriksaan MRI terdapat beberapa metode untuk menghasilkan citra dengan kontras berdasarkan klinis untuk memudahkan radiolog dalam menghasilkan diagnosa. Beberapa metode yang digunakan yaitu dengan mengatur penggunaan sequence dan penggunaan media kontras gadolinium yang diinjeksikan melalui intra vena.

Menurut J.C. Ferre at.all. (2013), penggunaan sequence perfusi pada MRI mampu memberikan informasi fungsional jaringan mengenai karakteristik lesi dan prognosis pada beberapa patologi khususnya untuk melihat CBF (Cerebral Blood Flow). Untuk menghasilkan citra CBF biasanya digunakan sequence DSC (Dynamic Susceptibility Contrast). Sequence DSC menghasilkan beberapa citra perfusi (CBF, CBV dan MMT) dengan prosedur menginjeksikan media kontras gadolinium dengan flow rate tertentu ke dalam tubuh pasien. Teknik sequence DSC ini masuk dalam kategori teknik invasive karena diperlukan injeksi media kontras untuk dapat menghasilkan perfusi pada jaringan. Kemudian pada tahun 2009 Jeffrey M. Pollock, MD et.all 
mengembangkan teknik 3D ASL (Arterial Spin Labeling) pada pemeriksaan MRI brain untuk mengetahui perfusion cerebral blood flow tanpa menggunakan media kontras.

\section{Metode}

Jenis penelitian ini adalah penelitian kualitatif dengan pendekatan studi kasus. Data diambil pada bulan Januari sampai Februari 2019. Obyek penelitian yaitu pemeriksaan MRI Brain pada kasus CVA infract di Instalasi Radiologi RS Adi Husada Undaan Wetan Surabaya. Subyek penelitian adalah 2 orang radiografer dan 1 orang radiolog yang berpelangan dalam MRI.

\section{Hasil dan Pembahasan}

1. Paparan Kasus dan Riwayat Pasien

Seorang pasien perempuan berusia 42 tahun melakukan pemeriksaan MRI Brain Non Contrast dengan klinis suspect CVA Infract hemipharese dextra. Pasien datang ke instalasi Radiologi Rumah Sakit Adi Husada Undaan Wetan Surabaya dalam kondisi tidak sadar setelah makan malam, kemudian dibawa ke IGD untuk diobservasi oleh dokter dan dilakukan pemeriksaan MRI Brain Non Contrast.

2. Prosedur Pemeriksaan MRI Brain dan Aplikasi sequence 3D ASL

Prosedur pemeriksaan MRI Brain non contrast di Instalasi Radiologi Rumah Sakit Adi Husada Undaan Wetan Surabaya diawali dengan inform concent kemudian melakukan screening meliputi berat badan pasien; riwayat penyakit dan keluhan pasien; riwayat tindakan operasi, CT-Scan dan MRI; dan implant berbahan logam pada tubuh pasien. Selanjutnya pasien diminta untuk mengganti pakaian dengan baju pasien sebelum masuk ke ruangan MRI. Persiapan pasien yang dilakukan di Radiologi Rumah Sakit Adi Husada Undaan Wetan Surabaya sudah sesuai dengan teori Moeller dan Reif (2010) dan Westbrook (2014) yang menyatakan bahwa pada pemeriksaan MRI Brain non contrast tidak ada persiapan khusus.

Pemeriksaan MRI Brain Non Contrast di Instalasi Radiologi RS Adi Husada Undaan Wetan Surabaya menggunakan alat MRI GE 1,5 T Signa Explorer dengan Neuro Vascular (NV) Coil. Pasien diposisikan supine head first pada couch MRI dengan posisi objek pada pertengahan coil NV.
Pasien dipasangkan earplug dan atau headphone untuk fiksasi dan kenyamanan pasien. Kemudian pasien diberikan emergency buzzer untuk keamanan pasien. Selanjutnya registrasi input data pasien pada system console dan dilakukan scanning menggunakan sequence MRI Brain routine pada klinis suspect CVA infarct meliputi Ax DWI b1000, Ax T2 Flair FS, Ax T2 Propeller, Ax T1 FSE, MRA TOF, Ax T2* GRE. Hasil citra dari sequence tersebut adalah sebagai berikut:
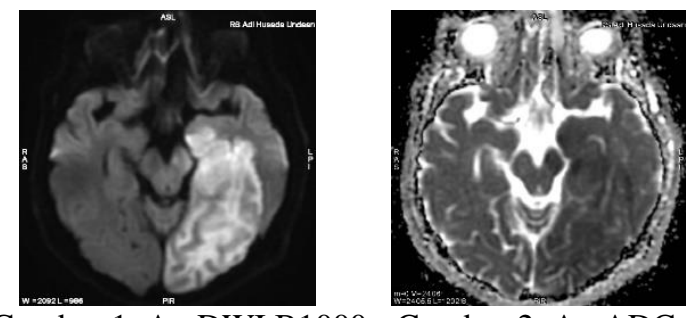

Gambar 1. Ax DWI B1000
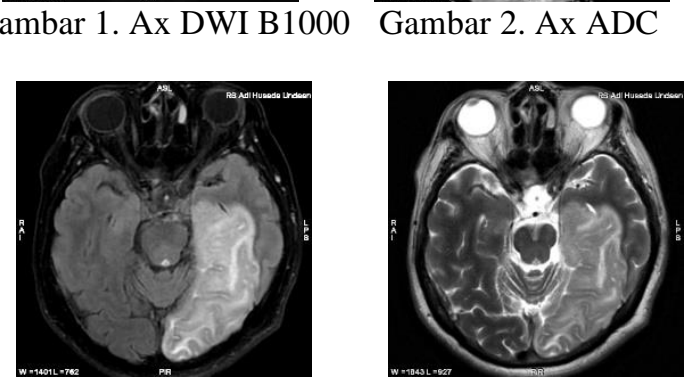

Gambar 3. Ax T2 Flair FS

Gambar 4. Ax T2 Propeller

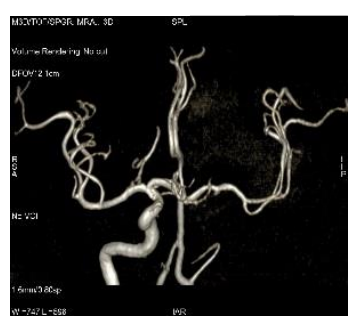

Gambar 5. MRA TOF

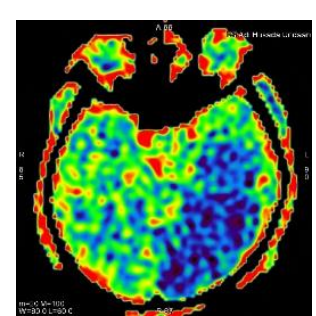

Gambar 6. 3D ASL
Setelah dilakukan scanning pada sequence Ax DWI b1000 (gambar 1) tampak gambaran restricted area pada capsula interna, thalamus, globus pallidus, putamen, corona radiata kiri. Pada sequence Ax T2 Flair FS (gambar 3) dan Ax T2 Propeller (gambar 4) menunjukkan hyperintens pada daerah yang sama yang ditunjukkan pada gambar 1 . Hasil sequence MRA TOF (gambar 5) pada daerah left inferior carotid artery (LICA) tidak muncul lumen artery, kemudian dilakukan penambahan sekuen 3D ASL untuk mengetahui CBF (gambar 6).

Aplikasi sequence 3D ASL dilakukan berdasarkan hasil scanning dari MRI brain routin tersebut. Hasil gambar pada Ax DWI b1000 terlihat hyperintens pada daerah capsula interna, thalamus, globus pallidus, putamen, corona radiata kiri dan hypointens pada gambaran ADC (Apparent Diffusion Coeficient). Hal ini menunjukkan adanya 
suatu kelainan patologis pada daerah tersebut (restricted area). Sekuen Ax T2 Flair FS dan Sekuen Ax T2 Propeller menunjukkan gambaran hyperintens pada daerah capsula interna, thalamus, globus pallidus, putamen, corona radiata kiri. Pada sekuen MRA TOF menunjukkan adanya penyumbatan pada pembuluh darah Left Inferior Carotid Artery (LICA). Radiografer mempunyai peran yang cukup penting sebagai decision maker untuk menentukan kapan harus menggunakan sekuen 3D ASL. Dalam kasus ini terdapat sumbatan pada pembuluh darah LICA sehingga parenchym otak bagian capsula interna, thalamus, globus pallidus, putamen, corona radiata kiri tidak mendapatkan suplai darah dan dapat mengakibatkan jaringan tersebut menjadi jaringan necrotic. Dokter pengirim mengirimkan permintaan untuk pemeriksaan MRI Brain Non Contrast, sehingga tidak ada hasil pemeriksaan Bun dan Creat (tidak bisa dilakukan Dynamic Susceptibility Contrast). Salah satu alternatif yang digunakan dengan menggunakan sekuen 3D ASL (Arterial Spin Labeling) untuk mengetahui cerebral blood flow.

Parameter yang perlu diperhatikan untuk menghasilkan 3D ASL yang akurat adalah Post labeling delay (PLD). Selain parameter Post Labeling Delay (PLD), posisioning kepala juga menentukan hasil dari 3D ASL, karena pada protocol 3D ASL kita tidak bisa melakukan penyudutan (tilting) untuk mensimetriskan area yang akan dilakukan scanning sehingga posisi yang baik akan menghasilkan grafik yg baik pula. Sekuen 3D ASL juga sangat sensitive terhadap susceptibility artifact, jadi pastikan ketika melakukan scanning pasien masuk ke ruangan sudah dalam kondisi terbebas dari logam. Parameter Post Labeling Delay diatur berdasarkan usia pasien untuk menentukan waktu yang diperlukan aliran darah dari artery carotis hingga mencapai ke brain pharencyma. Ada beberapa nilai pada parameter Post Labeling Delay, nilai PLD 1025 digunakan pada rentang usia 0-15 tahun, nilai PLD 1525 digunakan pada rentang usia 16-40 tahun, nilai PLD 2025 digunakan pada rentang usia 40-50 tahun, nilai PLD 2525 digunakan pada rentang usia 50-75 tahun, nilai PLD 3025 digunakan pada rentang usia 75 tahun keatas. (GE Healthcare). Dalam kasus ini sesuai dengan umur pasien maka digunakan post labeling delay 2025. Dengan adanya informasi mengenai Cerebral blood flow mempermudah radiologist dalam menegakkan suatu diagnosa. Penggunaan sekuen 3D ASL (Arterial Spin Labeling) bisa juga diaplikasikan pada klinis lain, misal Hemangioma pada brain, dimana pada daerah mass menunjukkan hyperperfusion.

\section{Simpulan}

Aplikasi sequence 3D ASL pada klinis suspect CVA infarct dengan metode yang tepat dapat dapat sangat membantu radiolog untuk menegakkan diagnosa kelainan pasien. Pada klinis lain sequence 3D ASL dapat diaplikasikan untuk memberikan informasi mengenai cerebral blood flow. Pada pasien yang memiliki kelainan pada ginjal, sequence ini dapat menjadi alternative karena tidak memerlukan media kontras.

\section{Daftar Pustaka}

Jeffrey M. Pollock, MD. 2009. Arterial Spin Labeled MRI Perfusion Imaging: Clinical Applications.

J.-C. Ferre. 2013. Arterial Spin Labeling (ASL) Perfusion: Techniques and clinical use.

Moeller and Reif. 2000. Atlas of Sectional Anatomy, Computer Tomography and Magnetic Resonance Imaging. Thiem Stuttgart : New York.

Sven Haller, MD, MSc. 2016. Arterial Spin Labeling Perfusion Of The Brain: Emerging Clinical Applications.

Westbrook C. 2014. Handbook of MRI technique, Fourth Edition, W. B.. Sounders Company, Canada. 